\title{
Distinguishing benign notochordal cell tumors from vertebral chordoma
}

\author{
Takehiko Yamaguchi • Jun Iwata • Shinsuke Sugihara • \\ Edward F. McCarthy Jr. • Michiaki Karita • \\ Hideki Murakami • Norio Kawahara • \\ Hiroyuki Tsuchiya $\cdot$ Katsuro Tomita
}

Received: 5 January 2006 /Revised: 8 November 2007 / Accepted: 5 December 2007 / Published online: 8 January 2008

(C) ISS 2007

\begin{abstract}
Objective The objective was to characterize imaging findings of benign notochordal cell tumors (BNCTs).

Design and patients Clinical and imaging data for 9 benign notochordal cell tumors in 7 patients were reviewed
\end{abstract}

This material was presented at the 20th European Congress of Pathology in Paris, September 2005 and at the 32nd Closed Meeting of the International Skeletal Society in Singapore, September 2005.

To the memory of Dr. Darby, who documented the first clinical case of this unique condition.

T. Yamaguchi $(\bowtie)$

Department of Surgical Pathology,

Sapporo Medical University School of Medicine,

S1W16 Chuo-ku,

Sapporo, Hokkaido 060-8543, Japan

e-mail: dokkyomed@mac.com

J. Iwata

Department of Laboratory Medicine,

Kochi Health Science Center,

2125-1 Ike,

Kochi, Kochi 781-8555, Japan

\section{S. Sugihara}

Department of Orthopaedic Surgery,

Kochi Health Science Center,

2125-1 Ike,

Kochi, Kochi 781-8555, Japan

E. F. McCarthy Jr.

Department of Pathology, The Johns Hopkins Hospital,

600 North Wolfe Street,

Baltimore, MD 21287, USA

M. Karita $\cdot$ H. Murakami $\cdot$ N. Kawahara $\cdot$ H. Tsuchiya $\cdot$ K. Tomita Department of Orthopaedic Surgery, Kanazawa University,

13-1 Takaramachi,

Kanazawa, Ishikawa 920-8641, Japan retrospectively. Conventional radiographs $(n=9)$, bone scintigrams $(n=2)$, computed tomographic images $(n=7)$, and magnetic resonance images $(n=8)$ were reviewed. Eight of the 9 lesions were stained with hematoxylin-eosin and microscopically examined.

Results There were 3 male and 4 female patients with an age range of 22 to 55 years (average age, 44 years). Two patients had two lesions at different sites. The lesions involved the cervical spine in 4 patients, the lumbar spine in 2 , the sacrum in 2 , and the coccyx in 1 . The most common symptom was mild pain. The lesions of 2 patients were found incidentally during imaging studies for unrelated conditions. Five patients underwent surgical procedures. One patient died of surgical complications. All other patients have been well without recurrent or progressive disease for 13 to 84 months. Radiographs usually did not reveal significant abnormality. Five lesions exhibited subtle sclerosis and 1 showed intense sclerosis. Technetium bone scan did not reveal any abnormal uptake. Computed tomography images had increased density within the vertebral bodies. The lesions had a homogeneous low signal intensity on T1-weighted magnetic resonance images and a high intensity on T2-weighted images without soft-tissue mass. Microscopically, lesions contained sheets of adipocyte-like vacuolated chordoid cells without a myxoid matrix. Conclusions Benign notochordal cell tumors may be found during routine clinical examinations and do not require surgical management unless they show extraosseous disease. These tumors should be recognized by radiologists, pathologists, and orthopedic surgeons to prevent operations, which usually are extensive.

Keywords Spine - Vertebra - Benign notochordal cell tumor . Notochordal hamartoma $\cdot$ Notochordal rest $\cdot$ Chordoma . MRI 


\section{Introduction}

The giant notochordal rest and notochordal hamartoma are terms that have been used to describe a benign notochordal cell tumor (BNCT) that may be mistaken for a chordoma $[1,2]$. This recently discovered intraosseous benign lesion of notochordal cell origin may be a potential precursor of chordoma [3-6], but based on the few cases with long-term follow-up (those previously published and our present series) none has clinically grown to become a chordoma. The anatomical predilection is identical to that of chordoma. The most common locations are the sacro-coccygeal region and the base of the skull, followed by cervical and lumbar vertebrae. Most tumors are usually small and asymptomatic and are often found at autopsy. The occasional lesion may become large and can be detected on advanced imaging. Our working group collected 7 cases of BNCT that were detected on imaging. We report on their management, outcomes, and histology. Five patients underwent surgical management based on a misdiagnosis of chordoma and failure to recognize the entity of BNCT. This paper focuses on the clinical, radiological, and histological features of these cases, which get overtreated when misdiagnosed.

\section{Materials and methods}

The data came from 7 patients with BNCTs that were found clinically. Clinical records included patient sex, age, presenting symptoms, and anatomic site involved. All formalin-fixed specimens were decalcified with formic acid solution and then routinely processed for hematoxylin-eosin and periodic acid Schiff (PAS) staining. For immunohistochemical study, paraffin-embedded specimens were cut into 3- to 5- $\mu$ m-thick sections and then mounted on glass slides coated with 3aminopropyltriethoxysilane. The sections were stained by the streptavidin-biotin-peroxidase method (Nichirei, Tokyo, Japan). The antibodies used are listed in Table 1. Microwave antigen retrieval was carried out prior to immunostaining with vimentin, AE1/AE3, CAM 5.2, and cytokeratin (CK) 18. To determine the specificity of immunostaining, we included known positive and negative tissues as controls.

\section{Results}

Table 2 summarizes ages, symptoms, treatment, and outcomes of the 7 patients with BNCTs that were found clinically (Figs. 1, 2). Two lesions were documented as possible vertebral osteonecrosis without collapse; however, recent histological re-evaluation indicated BNCTs [7, 8]. The other cases were originally diagnosed as chordoma histologically. The patient group consisted of 3 men and 4 women ranging in age from 22 to 55 years (mean, 44 years). One patient was found to have two lesions at different sites, evident in the fifth lumbar vertebra and the second sacral vertebra (Fig. 3). The latter was not examined microscopically. A small lesion was found incidentally in another patient in the far distal coccyx and was resected. Of the 9 lesions, 4 were in the cervical vertebra; 2 each in the lumbar vertebra and sacrum; and 1 in the coccyx. The most common symptom was pain in 5 patients; however, 1 patient complained of pain radiating to the fingers and numbness that possibly was caused by known ossification of the posterior longitudinal ligament (OPLL) at the sixth to seventh cervical vertebrae. Another patient was found to have cervical OPLL on radiographs. The pain was usually indolent except for that caused by OPLL. Lesions were found incidentally in 2 patients on MR images when they were examined for unrelated symptoms due to traffic accidents. A needle or open biopsy was done for 5 lesions. Four lesions were diagnosed as chordoma and 1 as osteonecrosis. The remaining 2 lesions were clinically diagnosed as osteonecrosis and an intraosseous benign condition respectively. The patients whose lesions were diagnosed as osteonecrosis and chordoma respectively underwent curettage. Three patients underwent vertebrectomy after the diagnosis of chordoma. One patient underwent wide resection following a preceding curettage. One patient who did not undergo a surgical procedure was followed because the diagnosis of osteonecrosis was made at biopsy. Another patient did not undergo any surgical management in spite of the histological diagnosis of chordoma at biopsy and was followed because the clinician doubted the histological diagnosis of chordoma based on unusual radiological findings for chordoma. The prognosis of all patients but 1 was excellent. Four patients who underwent surgical management were well without recurrent or metastatic disease for follow-up periods between 17 and 84 months (mean 54.5 months). Two patients who did not undergo surgery were alive without progressive disease, as judged by imaging, for 13 months and 44 months after biopsy respectively (Fig. 4). One patient who underwent vertebrectomy died of hemostasis after surgery because she would not accept a blood transfusion on religious grounds.

Imaging findings

Clinical images reviewed included conventional radiographs $(n=9)$, bone scintigrams $(n=2), \mathrm{CT}$ scan $(n=7)$, and MR imaging $(n=8)$. Conventional radiographs revealed illdefined, vague sclerosis within the vertebral body in 5 lesions (Figs. 1, 2) and diffuse prominent sclerosis presenting as ivory vertebra in 1 (Fig. 3). The remaining 3 lesions were not identified on radiographs. In all 4 lesions involving 
Table 1 Antibodies used in the study

\begin{tabular}{lllc}
\hline Antibodies & Source & Clonality & Dilution \\
\hline Epithelial membrane antigen & DAKO Cytomation, Glostrup, Denmark & M & $1: 100$ \\
Cytokeratin (AE1/AE3) & DAKO Cytomation, Glostrup, Denmark & M & $1: 100$ \\
Cytokeratin (CAM5.2) & Becton Dickinson, San Jose, CA, USA & M & $1: 1$ \\
Cytokeratin 18 & DAKO Cytomation, Glostrup, Denmark & M & $1: 20$ \\
Vimentin & DAKO Cytomation, Glostrup, Denmark & P & $1: 100$ \\
S-100 protein & Nichirei, Tokyo, Japan & $1: 200$ \\
\hline
\end{tabular}

M, monoclonal; P, polyclonal.

the cervical spine, physiological lordosis was decreased. Bone scintigrams did not reveal any abnormal uptake.

All lesions were sclerotic on CT. One was mildly sclerotic in the center of the vertebral body. The others were moderately to markedly sclerotic (Figs. 1, 2). Among them, 5 lesions that were located in the central part of the vertebral body extended partly to the cortex. Another lesion had diffuse sclerosis replacing the entire bone marrow space. No cortical disruption or bone destruction was evident in any of the lesions.

T1-weighted MR images revealed an intraosseous lesion with homogeneous low signal intensity (Figs. 1-3). T2- weighted MR images revealed homogeneous intermediate to bright signal intensity. Gadolinium-DTPA-enhanced T1weighted MR images were available for 3 lesions and did not show any significantly increased intensity (Fig. 1). Three lesions occupied the entire marrow space and the other 5 lesions were surrounded by residual bone marrow tissue. No extraosseous disease was demonstrated.

\section{Histological findings}

Eight lesions were histologically examined. All lesions were located within the vertebral bodies. The lesions were

Table 2 Summary of benign notochordal cell tumors found clinically

\begin{tabular}{|c|c|c|c|c|c|c|c|}
\hline Patient & Age (years) & Gender & Location & Symptoms & Treatment & $\begin{array}{l}\text { Original } \\
\text { diagnosis }\end{array}$ & $\begin{array}{l}\text { Follow-up } \\
\text { information }\end{array}$ \\
\hline 1 & 30 & Male & L4 & Low back pain & $\begin{array}{l}\text { Vertebrectomy } \\
\text { following biopsy } \\
\text { and curettage }\end{array}$ & Chordoma & $\begin{array}{l}\text { Alive with no } \\
\text { evidence of } \\
\text { disease, } 60 \text { months }\end{array}$ \\
\hline 2 & 53 & Female & C6 & $\begin{array}{l}\text { Numbness and pain } \\
\text { of the fingers bilaterally, } \\
\text { probably due to OPLL } \\
\text { at } C 6,7\end{array}$ & $\begin{array}{l}\text { Vertebrectomy } \\
\text { following biopsy }\end{array}$ & Chordoma & $\begin{array}{l}\text { Alive with no } \\
\text { evidence of disease, } \\
57 \text { months }\end{array}$ \\
\hline 3 & 55 & Female & $\mathrm{C} 5$ & $\begin{array}{l}\text { Neck pain, shoulder } \\
\text { stiffness }\end{array}$ & Biopsy & Chordoma & $\begin{array}{l}\text { Alive with no } \\
\text { progressive disease, } \\
13 \text { months }\end{array}$ \\
\hline 4 & 50 & Male & $\mathrm{C} 3$ & $\begin{array}{l}\text { Car accident injury } \\
\text { (incidentally found } \\
\text { on MRI) }\end{array}$ & Curettage & Osteonecrosis & $\begin{array}{l}\text { Alive with no } \\
\text { evidence of disease, } \\
84 \text { months }\end{array}$ \\
\hline 5 & 52 & Male & $\mathrm{C} 5$ & $\begin{array}{l}\text { Mild upper back pain } \\
\text { OPLL, focal }\end{array}$ & Needle biopsy & Osteonecrosis & $\begin{array}{l}\text { Alive with no } \\
\text { progressive disease, } \\
44 \text { months }\end{array}$ \\
\hline 6 & 22 & Female & $\begin{array}{l}\text { S4, Cox } \\
\text { (microscopic) }\end{array}$ & Buttock pain & $\begin{array}{l}\text { Wide resection } \\
\text { following curettage }\end{array}$ & Chordoma & $\begin{array}{l}\text { Alive with no } \\
\text { evidence of disease, } \\
17 \text { months }\end{array}$ \\
\hline 7 & 43 & Female & $\mathrm{L} 5, \mathrm{~S} 2$ & $\begin{array}{l}\text { Car accident injury } \\
\text { (incidentally found } \\
\text { on MRI) }\end{array}$ & $\begin{array}{l}\text { Vertebrectomy } \\
\text { following biopsy } \\
\text { at L5 }\end{array}$ & Chordoma & $\begin{array}{l}\text { Died of } \\
\text { postoperative } \\
\text { complications }\end{array}$ \\
\hline
\end{tabular}

L, lumbar vertebra; C, cervical vertebra; S, sacrum; Cox, coccyx; OPLL, ossification of posterior longitudinal ligament. 


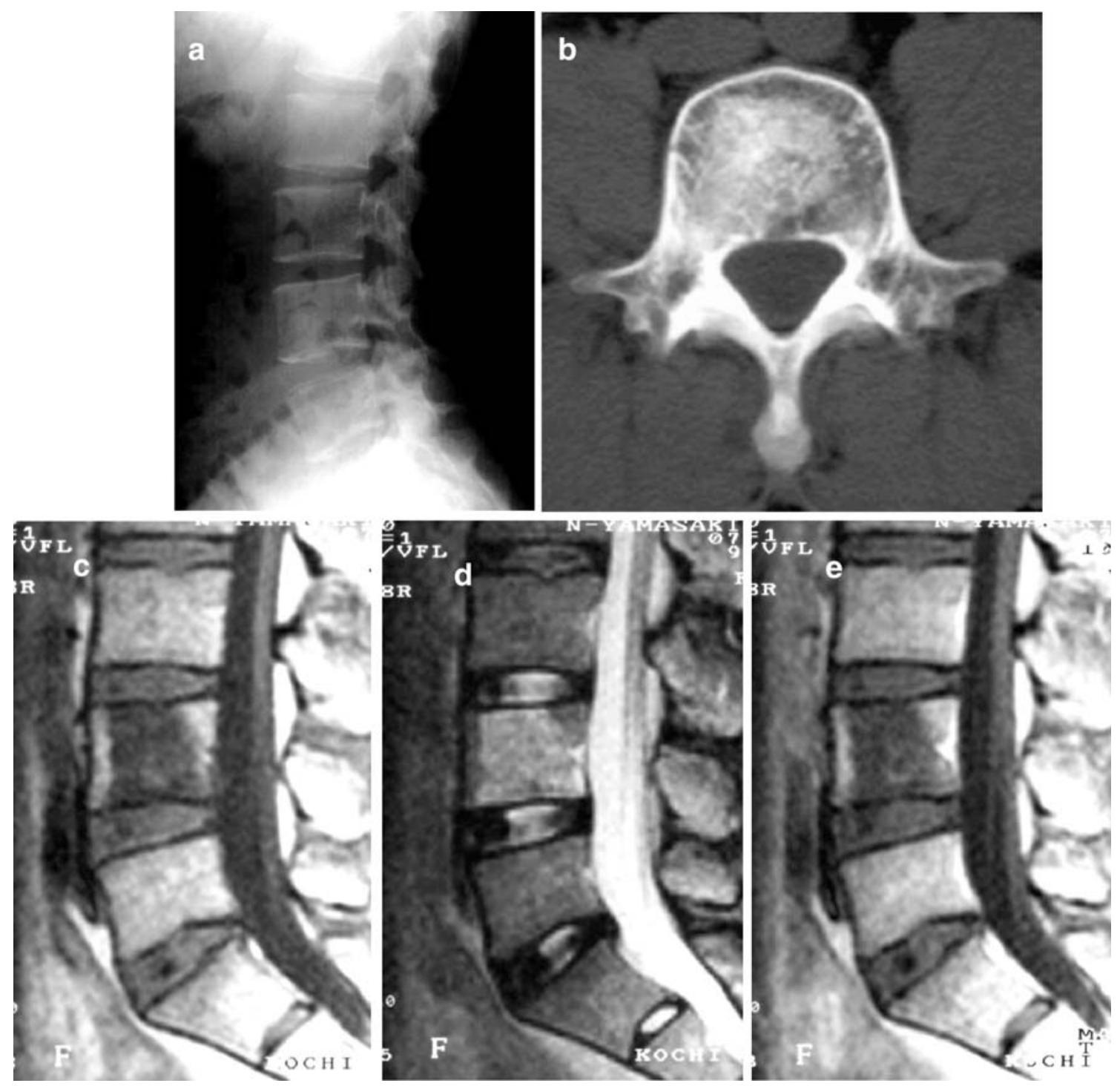

Fig. 1 A 30-year-old man who complained of low back pain (patient 1). a Lateral radiograph of the lumbar spine reveals vague sclerosis in the fourth lumbar vertebra. b Axial computed tomography (CT) scan of the fourth lumbar vertebra demonstrates significant sclerosis in the center of the body, partly extending to the cortex. c Sagittal T1-weighted spin echo magnetic resonance (MR) image reveals a large intraosseous lesion with low signal intensity. The normal bone marrow signal is preserved in the anterior and posterior portions of the body. $\mathbf{d}$ Sagittal T2-weighted MR image shows slightly bright signal intensity intermingled with intermediate signal. e Sagittal gadolinium-DTPA-enhanced MR image does not demonstrate any enhancement. No soft tissue mass is recognized unencapsulated and composed of solid sheets of adipocytelike vacuolated chordoid cells mixed with eosinophilic, less vacuolated cells of various degrees (Fig. 5a). The adipocytelike cells had clear cytoplasm and eccentrically or centrally located round or polygonal nuclei (Fig. 5b). Some tumor cells were multi-vacuolated and their nuclei were mildly polymorphic or hyperchromatic (Fig. 5c). No mitotic figures were recognized in any of the lesions. No myxoid background was evident. In some cases, cystic spaces were found in the lesions that contained eosinophilic colloid-like material. The lesions lacked any apparent vascular network. Islands of hematopoietic bone marrow were seen within the lesions. The entrapped bone trabeculae were sclerotic because of appositional or reactive new bone formation (Fig. 5a,b). PAS staining demonstrated intracytoplasmic glycogen granules. In all 7 lesions examined immunohistochemically, the tumor cells stained intensely positive for vimentin, S-100 protein, EMA, CAM5.2, AE1/AE3, and CK18 (Fig. 5d,e). The appearance in each of the cases was consistent with benign notochordal cell tumor $[4,5]$. There 


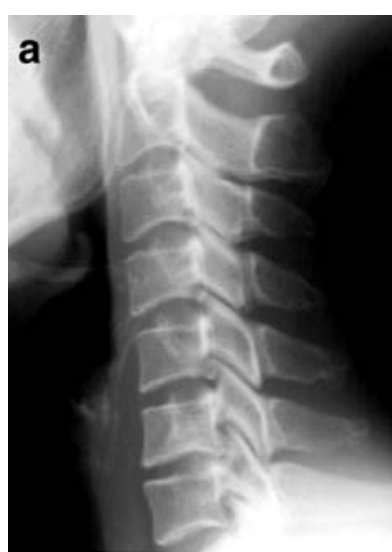

Fig. 2 A 53-year-old woman who was examined for ossification of the posterior longitudinal ligament at the sixth to seventh cervical vertebrae (patient 2). A lesion was found incidentally. a Lateral radiograph reveals faint or vague osteosclerosis in the 6th cervical vertebral body. The physiological lordosis of the cervical spine is decreased. b Axial CT
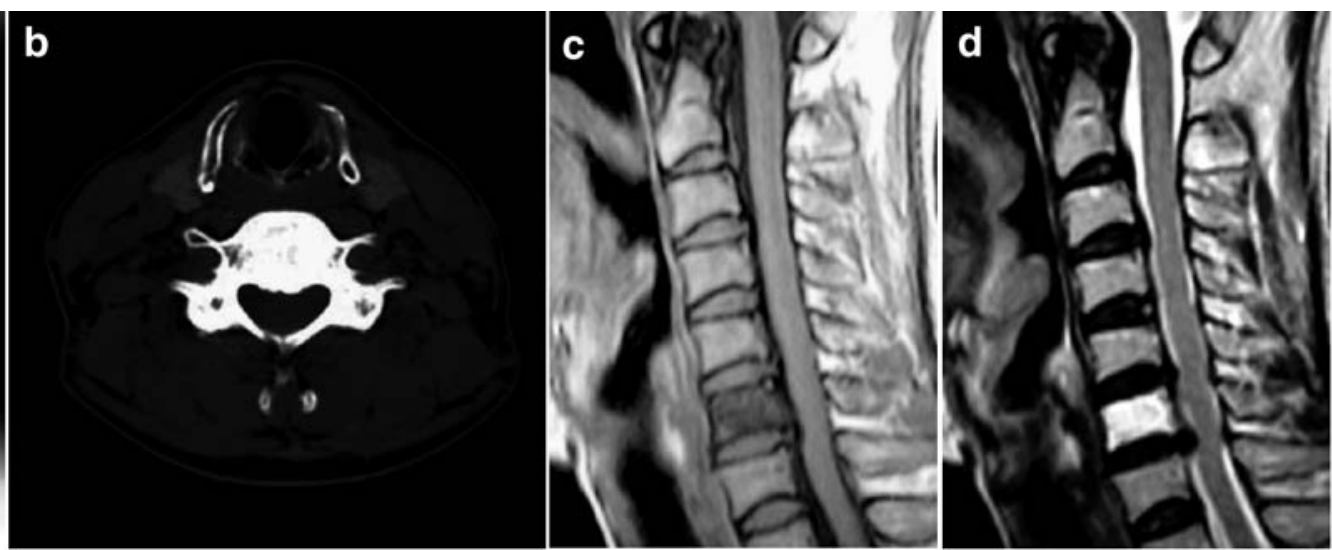

scan reveals diffuse sclerosis within the vertebral body. c Sagittal T1weighted spin echo MR image reveals low signal intensity in almost the entire marrow space of the sixth cervical vertebra. d Sagittal T2weighted MR image reveals intensely high signal replacing the entire marrow space. No soft tissue mass is evident were no features to support the diagnosis of chordoma. Patient 7 was presented at the Members Meeting of the International Skeletal Society in 1999.

\section{Discussion}

Six lesions consistent with BNCT have been documented previously by others [1, 2, 9-11]. Darby and coauthors [1] first described a case in 1999, which was surgically excised. A 39-year-old man who complained of a 7-week history of persistent low back pain was found to have an intraosseous lesion replacing almost the entire fifth lumbar vertebra. Radiographs and scintigraphy appeared normal. The lesion was well visualized by MRI, but showed only mild sclerosis on a CT scan. Histological findings were identical to those of our cases presented here. They were not typical for chordoma; however, the authors suspected that the

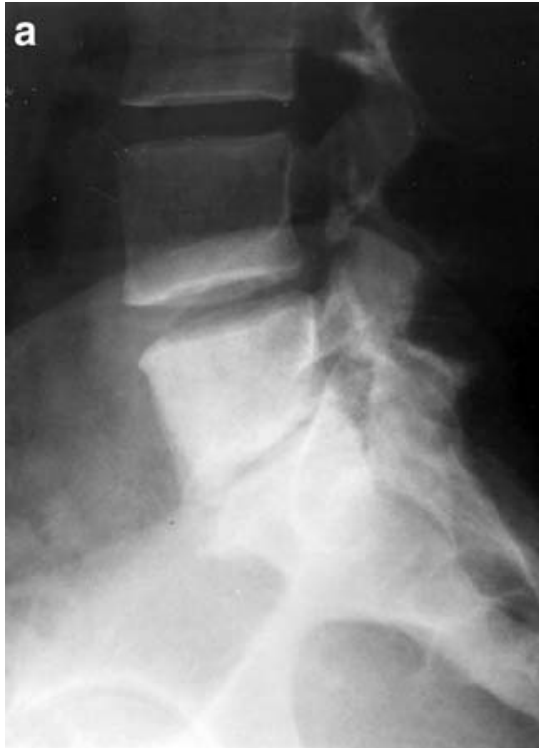

Fig. 3 A 43-year-old woman who was found to have two separate abnormalities in the lower spine during an imaging study for a traffic accident (patient 7). a Lateral radiograph of the lumbar spine and sacrum reveals intense sclerosis of the entire fifth lumbar vertebral

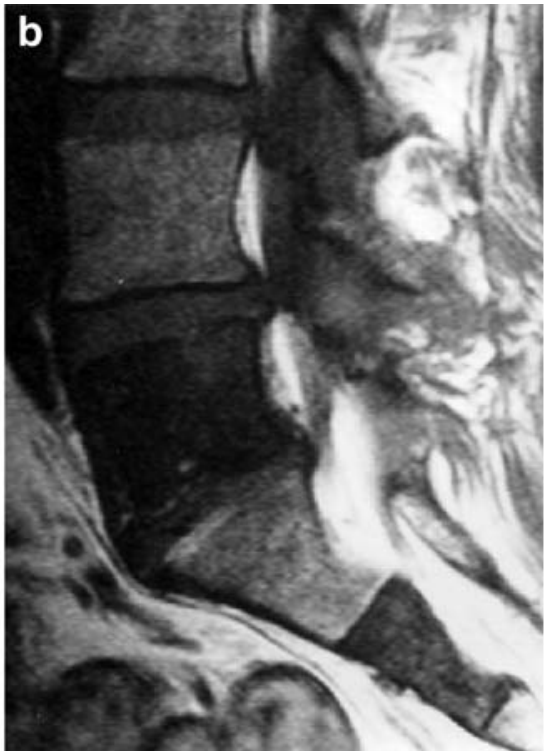

body and mild sclerosis in the cephalad portion of the sacrum. b Sagittal T1-weighted MR image reveals homogeneous low signal intensity in both the fifth lumbar and second sacral vertebrae 


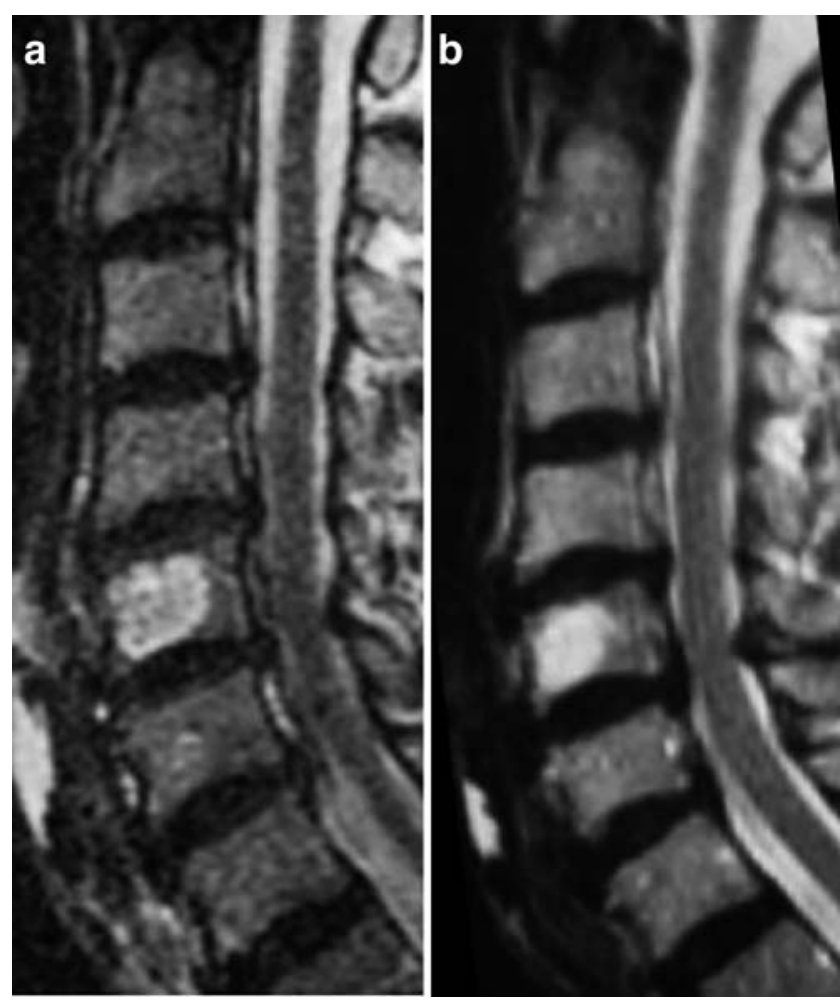

Fig. 4 A 52-year-old man who complained of mild upper back pain (patient 5). a Sagittal T2-weighted MR image reveals an intraosseous lesion with high signal intensity in the fifth cervical vertebra at initial presentation. b Sagittal T2-weighted MR image demonstrates no progressive disease 14 months after needle biopsy. No extraosseous tumor extension or enlargement is recognized

lesion might be an intraosseous chordoma rather than a giant notochordal rest. Mirra and Brien [2] reported 2 cases under the name of giant notochordal hamartoma of intraosseous origin. A 42-year-old woman complained of low back pain after falling down the stairs and was found to have an intraosseous lesion involving almost the entire sixth thoracic vertebral body on MRI. The other case was a 41-year-old man who had suffered from intermittent stiffness and mild pain in the neck. MR images demonstrated an intraosseous lesion involving about $98 \%$ of the fifth cervical vertebral body. Neither of the lesions was visible on radiographs. CT scans revealed osteosclerosis in the center of the affected vertebral bodies. The lesions showed low signal intensity on T1-weighted MR images and intermediate to high signal intensity on T2-weighted images and no extraosseous disease. No abnormal uptake was detected on bone scintigrams in either case. The patients did not undergo a surgical procedure after the biopsies. The follow-up examinations after 10 years and 38 months respectively demonstrated no progressive disease and indicated their benign nature. Kyriakos et al. [9] reported a case that involved the fourth lumbar vertebra. An 11-yearold boy with Tourette's syndrome had a 2.5-year history of repeated low back pain after a playground injury. Radiographs, CT scan, and single photon emission computed tomographic bone scan (SPECT) were normal. MRI revealed an intraosseous lesion with low T1- and high T2-weighted signal intensities within the fourth lumbar vertebral body. Cell block material obtained by a fine needle aspiration biopsy led to the diagnosis of chordoma, and the patient underwent L4 vertebrectomy. On subsequent evaluation, they concluded that the lesion was likely a giant notochordal rest rather than chordoma. The most recently documented case reported by Chauvel et al. [10] was an intraosseous lesion in the fifth lumbar vertebral body. The patient was a 45-year-old woman who had complained of low back pain for 2 years. Radiographs and bone scan were normal; however, CT scan revealed fine sclerosis in the L5 vertebra. MRI demonstrated an intraosseous lesion with homogenous low signal on T1-weighted image and high on T2-weighted image. The patient underwent L5 vertebrectomy because the lesion was histologically diagnosed as a chordoma on biopsy. The histological features from the L5 vertebra were similar to those of previously documented cases reported by Darby et al. [1], Mirra and Brien [2], and Kyriakos et al. [9]. A further case was illustrated in the textbook by Dorfman and Czerniak [11]. The lesion entirely occupied the third lumbar vertebra.

Recent studies have discovered unique benign notochordal cell lesions within axial bone that may be precursors of chordoma [3-6, 12]. The new term "benign notochordal cell tumor" was proposed for these lesions [4, 5]. Careful autopsy examination can identify the lesions in approximately $20 \%$ of adult cadavers $[4,5]$. They are usually tiny or small and found most frequently in both ends of the axial skeleton followed by the mobile spine. Their histological features are different from those of classic chordoma or notochordal vestiges in fetal intervertebral disks (Table 3). BNCTs are characterized histologically by intraosseous sheets of adipocyte-like vacuolated chordoid cells intermingled with less vacuolated eosinophilic cells of various degrees. The lesions were not lobulated. Some colloid-like material containing cystic spaces are seen in the lesions; however, the lesions lack any myxoid background. The nuclei are usually bland, but sometimes appear mildly atypical. No mitotic figures are recognized. The affected bone trabeculae are sclerotic because of appositional or reactive new bone formation. These histological features are completely identical to those of the lesions reported by Darby et al. [1], Mirra and Brien [2], Kyriakos et al. [9], Chauvel et al. [10], and Dorfman and Czerniak [11]. These reported cases are considered by us to represent BNCTs that grew and replaced almost the entire vertebrae.

Benign notochordal cell tumors are usually asymptomatic or indolent. Most lesions are overlooked, even at 


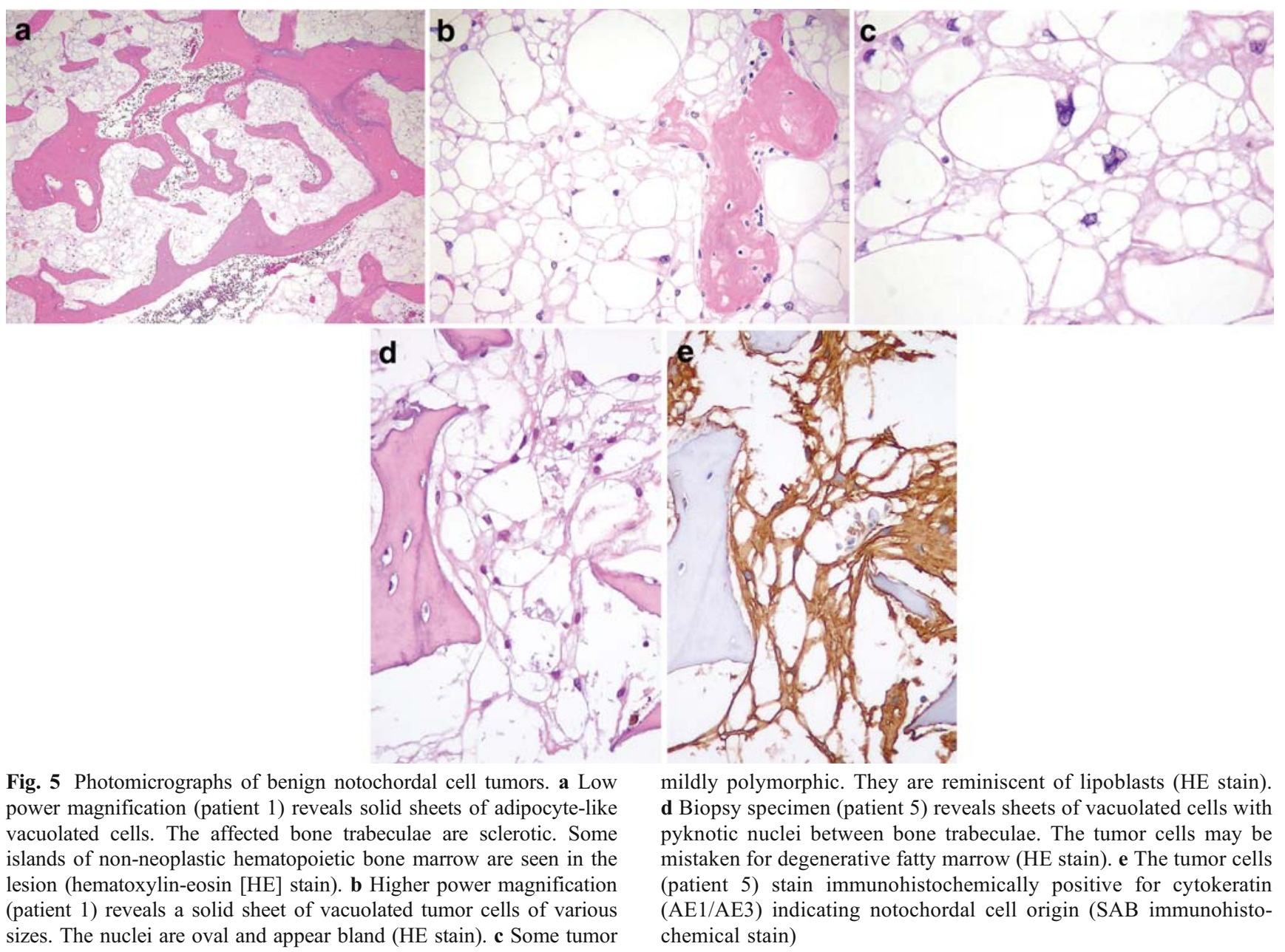

cells (patient 1) are multivacuolated and centrally located nuclei are

autopsy, because of their anatomical location or size. Only one such lesion had been documented with a name of ecchordosis physaliphora vertebralis in 1982 [13]. Enlarged BNCTs may be detected on CT or MR images, or rarely by conventional radiography. The imaging findings of our cases are somewhat variable, but distinctive in the absence of trabecular destruction on CT or of a soft tissue mass on either CT or MR images (Table 3). Gadolinium enhancement was absent in the 3 patients in whom it was administered. Radiographs may reveal ill-defined, vague sclerosis in the vertebral body and occasionally show diffuse sclerosis presenting as an ivory vertebra (Fig. 3). Often the lesions are invisible on radiographs. CT scans may reveal unequivocal sclerosis, which is much more obvious than on radiographs. No bone destruction or cortical disruption is recognized. T1-weighted MR images reveal relatively well-demarcated intraosseous lesions with homogeneous low signal intensity. T2-weighted MR images show homogeneous high signal intensity. GadoliniumDTPA enhanced T1-weighted MR images do not show enhancement. Bone scintigraphy did not show any abnormal uptake.

Diagnosis of the cases presented was based upon biopsy or preoperative imaging; the diagnosis was chordoma in 5 cases and osteonecrosis in 2. Hence, 5 patients underwent vertebrectomy, wide resection, or curettage. All patients but 1 are well without recurrent or metastatic disease. Two patients who underwent only biopsy had no progressive disease, as judged by radiography, CT, or MR images, for 13 months and 44 months respectively. As described by Mirra and Brien, the follow-up information was consistent with the benign nature of the tumors.

The terminology of the lesions is controversial. Dorfman and Czerniak [11], Kyriakos et al. [9] and Chauvel and coauthors [10] used the term giant notochordal rest. Mirra and Brien [2] proposed the term giant notochordal hamartoma of intraosseous origin. In addition, the International Skeletal Society has used the term benign chordoma on the brochure of the Pathology Refresher Course since 2003. However, we prefer the term "BNCT" 
Table 3 Imaging and microscopic features of benign notochordal cell tumors

\begin{tabular}{|c|c|}
\hline $\begin{array}{l}\text { Evaluation } \\
\text { method }\end{array}$ & Features \\
\hline $\begin{array}{l}\text { Radiograph } \\
(n=9)\end{array}$ & $\begin{array}{l}\text { Vague sclerosis }(n=5) \\
\text { Marked sclerosis }(n=1) \\
\text { Invisible }(n=3)\end{array}$ \\
\hline $\begin{array}{l}\text { Bone scintigram } \\
\quad(n=2)\end{array}$ & No abnormal uptake $(n=2)$ \\
\hline CT $\operatorname{scan}(n=7)$ & $\begin{array}{l}\text { Osteosclerosis in vertebral body }(n=7) \\
\text { No bone destruction or cortical disruption } \\
(n=7)\end{array}$ \\
\hline MRI $(n=8)$ & $\begin{array}{l}\text { T1-WI }(n=8) \text { : low signal intensity } \\
\text { T2-WI }(n=8) \text { : intermediate-high signal } \\
\text { intensity } \\
\text { Gd-DTPA T1-WI }(n=3) \text { : no enhancement } \\
\text { No invasive soft tissue mass }(n=8)\end{array}$ \\
\hline Histology $(n=8)$ & $\begin{array}{l}\text { Solid sheets of adipocyte-like vacuolated cells } \\
\text { combined with less vacuolated eosinophilic cells } \\
\text { of various degrees } \\
\text { Round or polygonal pyknotic nuclei occasionally } \\
\text { with polymorphism } \\
\text { No lobular configuration } \\
\text { No extracellular myxoid matrix } \\
\text { Some cystic spaces containing eosinophilic } \\
\text { colloid-like material } \\
\text { No mitotic figures } \\
\text { Poor vascular network } \\
\text { Entrapped islands of hematopoietic bone marrow } \\
\text { Sclerotic bone trabeculae affected } \\
\text { Positive immunostaining for vimentin, } \\
\text { cytokeratin (AE1/AE3, CK18), EMA, } \\
\text { and S-100 protein }\end{array}$ \\
\hline
\end{tabular}

CT, computed tomography; MR, magnetic resonance; WI, weighted image; Gd; gadolinium; CK, cytokeratin; EMA, epithelial membrane antigen.

to the others. BNCTs show histological and immunohistochemical features that are different from those of notochordal vestiges in fetal intervertebral disks. BNCTs lack any myxoid background and show positive immunoreactivity for cytokeratin 18 although notochordal vestiges in the fetal intervertebral disks are associated with myxoid matrix and are negative for cytokeratin 18. Notochordal vestiges are often found in the intervertebral disks of neonates and finally disappear by the age of 1 to 3 years. In our personal autopsy experience, we have never seen any notochordal tissue in the vertebral bodies in fetuses and babies who had notochordal vestiges in their intervertebral disks. In contrast, BNCTs are found in $20 \%$ of the axial skeleton dissected from adult cadavers. Therefore, BNCTs are considered to develop after birth. The term of hamartoma is not proper for the lesions, as mentioned by Kyriakos et al. [9] and one of the present authors [3]. The term of benign chordoma is oxymoronic because "chordoma" has been used to describe a malignant notochordal cell tumor [14].

In 15 clinically identified BNCTs, including our cases and those reported by others, 6 tumors were found in the lumbar spine, 5 in the cervical spine, 2 in the sacrum, and 1 each in the thoracic spine and coccyx. This anatomical distribution is different from that found at autopsy [2]. We believe the reason for this discrepancy is that the cervical and lumbar regions often are examined with MRI for neck pain and low back pain. Lesions in the sacrum and coccyx may be overlooked because they are less frequently imaged.

The most important disease that should be distinguished from BNCT is chordoma. Microscopically, chordoma is composed of cords or strands of atypical chordoid cells with a myxoid matrix of various degrees $[11,15,16]$. Chordomas are associated with a large soft tissue component. However, differential diagnosis may be difficult because cellular atypia of BNCT and chordoma may overlap. They also share the same immunohistochemical profile [3]. Imaging is critical in separating the benign lesion from the chordoma. Chordomas are osteolytic tumors. In contrast, BNCTs may show osteosclerotic reaction and do not exhibit osteolytic change. Chordomas are not intracompartmental lesions and are associated with a soft tissue mass. In those cases with histological overlap, with our present understanding of these diseases, we would suggest that the absence of a soft tissue mass should favor a BNCT and the presence of a soft tissue mass should indicate a chordoma.

Biopsy specimens of BNCTs may be easily mistaken for fatty marrow because of their morphological similarity to that tissue. Indeed, 2 lesions among our cases were overlooked as normal fat marrow on biopsy sections. Careful observation can distinguish BNCTs from fatty marrow. Furthermore, immunohistochemical study can help to distinguish BNCTs from fatty marrow. BNCTs stain positive for epithelial markers whereas fat cells do not (Fig. 5). Differential diagnosis also includes metastatic carcinoma, particularly originating from clear cell carcinoma of the kidney. Metastatic clear cell carcinoma usually is osteolytic on radiographs and CT scans. Gadolinium-DTPA enhanced T1-weighted MR images have increased signal intensity. Histologically, clear cell carcinoma has an alveolar pattern and vascular fibrous septa. Clear cell carcinoma rarely exhibits positive immunoreaction for S-100 protein [17].

Large BNCTs may be found during routine clinical examination. They may have the potential of malignant transformation to chordoma; however, the transformation, as we know from the collected cases, is a rare happening [6]. We, however, are not aware of any cases of what we term BNCT growing beyond the confines of bone and 
displaying features of chordoma, and therefore they should be managed as benign lesions and carefully followed by thin section CT and MRI for signs of extraosseous disease. More extensive follow-up by cross-sectional imaging over a long period of time would be required before firmly determining the biological behavior of BNCTs. BNCTs do not require any surgical management until they undergo malignant transformation. BNCTs should be recognized by radiologists, pathologists, and orthopedic surgeons to prevent unnecessary radical surgery and carefully followed by advanced imaging.

\section{References}

1. Darby AJ, Cassar-Pullicino VN, McCall IW, Jaffray DC. Vertebral intra-osseous chordoma or giant notochordal rest? Skeletal Radiol 1999; 28: 342-346.

2. Mirra JM, Brien EW. Giant notochordal hamartoma of intraosseous origin: a newly reported benign entity to be distinguished from chordoma. Report of two cases. Skeletal Radiol 2001; 30 : 698-709.

3. Yamaguchi T, Yamato M, Saotome K. First histologically confirmed case of a classic chordoma arising in a precursor benign notochordal lesion: differential diagnosis of benign and malignant notochordal lesions. Skeletal Radiol 2002; 31: 413418.

4. Yamaguchi T, Suzuki S, Ishiiwa H, Ueda Y. Intraosseous benign notochordal cell tumors: overlooked precursors of classic chordomas? Histopathology 2004; 44: 597-602.

5. Yamaguchi T, Suzuki S, Ishiiwa H, Shimizu K, Ueda Y. Benign notochordal cell tumors: A comparative histological study of benign notochordal cell tumors, classic chordomas and noto- chordal vestiges of fetal intervertebral disks. Am J Surg Pathol 2004; 28: 756-761.

6. Yamaguchi T, Watanabe-Ishiiwa H, Suzuki S, Igarashi Y, Ueda Y. Incipient chordoma: a report of two cases of early-stage chordoma. Mod Pathol 2005; 18: 1005-1010.

7. Murakami H, Kawahara N, Gabata T, Nambu K, Tomita K. Vertebral body osteonecrosis without vertebral collapse. Spine 2003; 28: E323-E328.

8. Murakami H, Kawahara N, Tomita K, Yamaguchi T. Re: Murakami H, Kawahara N, Gabata T, et al. Vertebral body osteonecrosis without vertebral collapse [letter to the editor]. Spine 2005; 30: 593-594.

9. Kyriakos M, Totty WG, Lenke LG. Giant vertebral notochordal rest: a lesion distinct from chordoma: discussion of an evolving concept. Am J Surg Pathol 2003; 27: 396-406.

10. Chauvel A, Taillat F, Gille O, et al. Giant vertebral notochordal rest: a new entity distinct from chordoma. Histopathology 2005; 47: 643-652.

11. Dorfman HD, Czerniak B. Bone tumors. St. Louis: Mosby;1998. p. $974-1008$.

12. Deshpande V, Nielsen GP, Rosenthal DI, Rosenberg AE. Intraosseous benign notochord cell tumors (BNCT): further evidence supporting a relationship to chordoma. Am J Surg Pathol 2007; 31: $1573-1577$.

13. Ulich TR, Mirra JN. Ecchordosis physaliphora vertebralis. Clin Orthop 1982; 163: 282-289.

14. Jaffe HL. Tumors and tumorous conditions of the bones and joints. Philadelphia: Lea \& Febiger; 1958. p. 451-461.

15. Mirra JM, Rocca CD, Nelson SD, Martens F. Chordoma. Fletcher CDM, Unni KK, Martens F, editors. World Health Organization classification of tumours. Pathology and genetics of tumours of soft tissue and bone. Lyon: IARC Press; 2002. p. 315-317.

16. Unni KK. Dahlin's bone tumors: general aspects and data on 11087 cases. 5th ed. Philadelphia: Lippincott-Raven; 1996. p. 291-305.

17. Murphy WM, Grignon DJ, Perlman EJ. Tumors of the kidney, bladder, and related urinary structures. AFIP Atlas of tumor pathology, 4th series. Washington DC: ARP; 2004. p. 109-160. 